\title{
Single Use Vial
}

National Cancer Institute

\section{Source}

National Cancer Institute. Single Use Vial. NCI Thesaurus. Code C43216.

A vial where a single dose of a parenteral drug product can be removed, and then the vial and its remaining contents can be disposed. 